\title{
Diagnóstico tardío de la infección por VIH
}

\section{Late diagnosis of HIV infection}

\author{
M. Díez Ruiz-Navarro
}

El tratamiento antirretroviral (TAR) de la infección por el virus de la inmunodeficiencia humana $(\mathrm{VIH})$ produce una gran disminución de la morbi-mortalidad en los pacientes con acceso a él, algo que todavía no es la norma en los países con pocos recursos. Al margen de la falta de acceso, el mayor obstáculo para lograr la plena efectividad del TAR es el desconocimiento que una parte de los infectados tienen de su situación, ya que, incluso en los países ricos, la proporción que se encuentra en esa situación oscila entre el 20-30\%. La existencia de una fracción de infectados con VIH sin diagnosticar tiene efectos deletéreos para los afectados y para el control de la epidemia ya que, al desconocer su infección, estas personas adoptan menos medidas preventivas, y como no reciben TAR son más infecciosas que las que sí lo hacen. Además, el tratamiento de los pacientes diagnosticados tardíamente es más caro por su peor situación inmunológica. Por estas razones, la promoción del diagnóstico temprano y el tratamiento de los enfermos es una prioridad de primer orden para el control de la epidemia de VIH en todo el mundo.

La historia natural de la infección por VIH y la poca especificidad de la enfermedad por seroconversión dificultan el proceso del diagnóstico, por lo que distintos organismos nacionales e internacionales han diseñado iniciativas para promover la prueba de $\mathrm{VIH}$, tanto en los centros sanitarios como en el ámbito comunitario. En diciembre de 2010, el Centro Europeo para el Control de la Enfermedad (ECDC en sus siglas en inglés) publicó un documento-guía para orientar el proceso de desarrollo, monitorización y evaluación de las estrategias nacionales de realización de la prueba del VIH en los países de la Unión Europea, que marca como base para cualquier estrategia nacional los siguientes principios: a) voluntariedad y confidencialidad del test de VIH, incluyendo consentimiento informado documentado, lo que no implica necesariamente la firma del paciente; b) garantía de acceso al tratamiento

Jefe del Área de Vigilancia Epidemiológica del VIH/sida y Comportamientos de Riesgo Centro Nacional de Epidemiología. Madrid

\section{Correspondencia:}

Mercedes Díez Ruiz-Navarro

Centro Nacional de Epidemiología

Avda. Monforte de Lemos, 5

28029 Madrid

E-mail: mdiez@isciii.es 
y a los servicios sanitarios y preventivos; c) compromiso político, incluyendo provisión de recursos suficientes y utilización coste-efectiva de éstos; d) políticas de reducción del estigma; e) eliminación de barreras financiero-legales, incluyendo las normas de obligatoriedad -excepto en donaciones de sangre y trasplantes-y promulgación de leyes antidiscriminatorias; f) participación de todos los implicados en el desarrollo e implantación de la estrategia de promoción de la prueba; g) inclusión de la prueba de VIH como parte integral de toda estrategia sanitaria relacionada de una u otra forma con el $\mathrm{VIH}^{1}$.

En España, en 2013, el 46,6\% de los nuevos diagnósticos de VIH notificados al Sistema de Información sobre nuevos diagnósticos de VIH (SINIVIH), presentaba menos $350 \mathrm{CD} 4 / \mu \mathrm{l}$ en la primera determinación tras el diagnóstico, lo que se considera diagnóstico tardío, y un 27,3\% presentaba menos de $200 \mathrm{CD} 4 / \mu \mathrm{l}$, por lo que en cualquier momento podía desarrollar alguna de las enfermedades definitorias de sida. Los más afectados por esta situación fueron los inmigrantes, sobre todo los latino-americanos o sub-saharianos, las personas que adquirieron el virus por contacto heterosexuales sin protección o tras inyectarse con material contaminado, los mayores de 40 años y los varones.

En nuestro país, toda persona que lo necesite puede hacerse la prueba de VIH de forma gratuita y confidencial en cualquier centro sanitario y en diversas ONG. Sin embargo, los datos previos (muy parecidos a los de otros países europeos) indican que casi la mitad de los nuevos diagnosticados ya padecen un grave deterioro de su inmunidad cuando se idéntica su infección. Para que esto no ocurra hay que aumentar la percepción de riesgo entre los grupos más afectados por el diagnóstico tardío, pero también es necesario que los profesionales sanitarios oferten la prueba de VIH con más frecuencia, siempre teniendo en cuenta las circunstancias epidemiológicas y clínicas de cada persona. Con este propósito, en 2014, el Ministerio de Sanidad, Servicios Sociales e Igualdad ha publicado la Guía de Recomendaciones para el Diagnóstico Precoz del VIH en el Ámbito Sanitario, que desarrolla indicaciones para ofertar la prueba del VIH en centros sanitarios, tanto en personas con sospecha clínica de infección por VIH como en aquellas asintomáticas ${ }^{2}$.

Meramente por razones de buena praxis médica, la prueba debe ofertarse a cualquier persona que presente signos y/o síntomas de infección por VIH o sida, es decir cuando haya indicios de primoinfección por $\mathrm{VIH}$, de enfermedades diagnósticas de sida o de las llamadas "enfermedades indicadoras", definidas en el proyecto "HIV Indicator Disease across Europe Study"; las enfermedades indicadoras comprenden todas las ligadas con mayor probabilidad a la infección por VIH, o aquellas en las que no diagnosticar el VIH podría tener consecuencias negativas para el pronóstico del paciente ${ }^{2}$.

Para las personas asintomáticas, la Guía distingue entre oferta obligatoria, rutinaria y dirigida de la prueba de VIH. Es obligatorio determinar si existe infección por VIH en los supuestos de donación de sangre, trasplante, injerto o implantación de órganos, estudios de donantes o usuarios relacionados con técnicas de reproducción humana asistida y obtención o recepción de semen. En cuanto a la oferta rutinaria de la prueba, esta debe hacerse a las mujeres embarazadas, los internos en establecimientos penitenciarios y a las personas de la población general que cumplan los tres criterios siguientes: a) ser sexualmente activas 
y tener entre 20 y 59 años; b) habérseles indicado una extracción de sangre en un centro de Atención Primaria por cualquier motivo; este criterio se ha seleccionado por razones de eficiencia y para facilitar la aceptabilidad; y c) residir en provincias cuyas tasas de nuevos diagnósticos de VIH en el grupo de 20-59 años de edad superen el percentil 75 en ese mismo grupo, calculado en los últimos tres años a nivel nacional. Finalmente, se hará una oferta dirigida de la prueba de VIH en los siguientes casos: a) personas que soliciten la prueba por sospechar una exposición de riesgo; b) parejas sexuales de personas infectadas por $\mathrm{VIH}$; c) personas inyectoras de drogas, o con antecedentes de haberlo sido, y sus parejas sexuales; d) HSH y sus parejas sexuales (hombres y mujeres); e) personas que ejercen la prostitución mujeres, hombres y transexuales, sus parejas sexuales y sus clientes; f) personas heterosexuales con más de una pareja sexual y/o prácticas de riesgo en los últimos doce meses; g) personas que deseen dejar de utilizar el preservativo con sus parejas estables; $h$ ) personas que hayan sufrido agresión sexual; i) personas que hayan tenido una exposición de riesgo al VIH, ocupacional o no ocupacional (accidental); y j) personas procedentes de países de alta prevalencia (>1\%) y sus parejas sexuales (2).

En este número de la revista Anales del Sistema Sanitario de Navarra se publica el artículo "Diagnóstico tardío de la infección por el virus de la inmunodeficiencia humana: oportunidades diagnósticas perdidas" ${ }^{3}$, cuyos datos, precisamente, permiten entrever el gran potencial de mejora que existe si se aplican correctamente las recomendaciones emitidas en el ámbito sanitario español. Según este artículo, cuatro de cada cinco pacientes diagnosticados de VIH en Navarra entre 2009 y 2013 contactaron con el sistema sanitario en los cinco años previos al diagnóstico, de los que 15\% tenían factores de riesgo clásicos para la infección por VIH documentados en la historia clínica, 11\% procedían de países con alta prevalencia de VIH y $35 \%$ habían presentado indicadores clínicos de infección por el VIH. A pesar de ello, solo al 21\% de estos pacientes se les realizó la prueba del VIH, lo que supone un gran número de oportunidades perdidas para el diagnóstico de la infección.

Es de esperar que la aplicación de las recomendaciones de la Guía para el Diagnóstico Precoz del VIH en el ámbito sanitario provoque un cambio en un sentido positivo en la situación descrita en el artículo, que muy probablemente representa más la norma que la excepción en las instituciones sanitarias de nuestro país.

\section{BIBLIOGRAFÍA}

1. European Centre for Disease Prevention and Control. HIV Testing: increase uptake and effectiveness in the European Union. Stockholm: ECDC; 2010.

2. Ministerio de Sanidad, Servicios Sociales e Igualdad. Guía de Recomendaciones para el diagnóstico precoz del VIH en el ámbito sanitario. Madrid, 2014.

3. Rivero Marcotegui M, Layana Echezuri E, Repáraz Padrós J, Irigoyen Olaiz C, Arraiza Cruchaga MJ, Ayestaraán Uriz J. Diagnóstico tardío de la infección por el virus de la inmunodeficiencia humana: oportunidades diagnósticas perdidas. An Sist Sanit Navar 2014; 37: 329-338. 